\title{
MATTELART REVISA A COMUNICAÇÃO E A SI PRÓPRIO
}

\section{Antonio Hohlfeldt}

Todo o livro de Armand Mattelart, independentemente de se concordar ou não com ele, é sempre importante e provocativo. No caso de seu novo trabalho, recentemente traduzido no Brasil, contudo, ele supera a si mesmo e surpreende seu leitor mais tradicional por uma espécie de renovaçáo na perspectiva de abordagem que propóe. Não se trata de dizer que Mattelart mudou, exatamente, ou que abandonou suas posiçōes, De modo algum. $\mathrm{O}$ que temos é uma amplitude de perspectiva tradicionalmente ausente de seus livros anteriores, demasiadamente marcados pela leitura militante mancista e maniqueista, onde os 'bandidos' usam e abusam da comunicaçấo contra a indefesa populaçāo.

Há textos que siào fundamentais na obra de Mattelart. Seu vanguardismo em uma obra como As Multinacionais da Cultura, por exemplo ou, para o Brasil, as análises contidas em O Carnaval das Imagens. Mas eram sempre, em última análise, e por um ou outro motivo, de enfoque ou de tema, abordagens localizadas. No caso deste Comunicação-Mundo, como seu titulo bern o sugere, o que temos é uma obra de abrangência surpreendente. na melhor tradiçầo dos enciclopedistas franceses, que esse belga retoma, $\mathrm{e}$ com uma enorme vantagem para nós, latino-americanos: é que seus pontosde-vista nos incluem e sua bibliografia amplíssima leva em consideraçâo obras teóricas igualmente produzidas em nosso continente

Comunicaçáo-Mundo divide-se claramente em dois blocos de estudo, o das idćas e o das estratégias. Para isso, o livro é arganizado sob triplice perspectiva, explicitada desde o prêambulo triangular: "a comunicascióo serve, antes de tudo, para fazer a guerra" ( p. 9); "a comunicaço serve para promover o progresso" ( p. 10), afirmativas que têm a ver com as estratégias; e "a comunicação é cultura" ( $\mathrm{p}, 11)$ o que diz respeito às idéias.

Pois é deste ponto de partida polêmico, desde logo, a subjugaçăo histórica aparente da comunicaçâo à perspectiva da guerra, que Mattelart

\begin{tabular}{|c|c|c|c|c|c|}
\hline R.FAMECOS & Porto Alegre & $n 3$ & $p \cdot 6-67$ & setembno 1995 & semetral \\
\hline
\end{tabular}


realiza uma espécie de inventário das conquistas tecnológicas que, sobrefudo a partir da segunda metade do século XIX, influenciaram fortemente na montagem de novas estratégias comunicacionais e as colocaram sob o guardachuva negro ou dos exércitos ou das policias. Uma das novidades pouco abordadas, em geral, neste tipo de análise, é a valorizaçáo do desenvolvimento das estradas de ferro a que se aliará o telégrafo e o telefone, o surgimento das agências de informaçầo e, enfim, a utilizaçào da comunicaçào ou seu controle como estrategia militar e política.

Desfilam neste capitulo, em consequência dats descobertas e das invençōes, algumas das primeiras teorias sobre os processos de comunicaçăo, como a do projétil ( p. 30), a disputa entre a perspectiva do monopólio público ou privado de alguns desses inventos e processos ( p5, 52.53), o surgimento de alguns questionamentos e práticas como a sociologia do lazer ( p. 44) e o romance folhetim ( $p .55)$, 50 compativeis com o avanço das comunicaçóes e o vistumbre das profundas modificaçôes que sobre a sociedade traziam tais conquistas. Harold Lasswell e sua famosa teoria dos $5 W_{5}(p .73)$ ainda hoje reiterada nas primeiras aulas de um curso de Comunicaçâo Social, e a abordagem pioneira e pouco ortodoxa, do ponto de vista do marxismo tradicional, de Antonio Gramsci, também sảo lembradas. O melhor deste bloco, contudo, é a perspectiva mais contemporănea que, partindo da guerra fria e dos estudos de Paul Lazarsfeld, Edward Hall e Claude Shannon, atingem dois pontos controvertidos: a eclosấo das guerrilhas e os movimentos de libertaçấo nacional e, sobretudo, as novfssimas e alarmantes novidades trazidas pela Guerra do Golfo que retoma debates dos tempos do Vietname, radicalizando-os, contudo, e lançando angustiantes indagaçoes sobre a ética no uso das comunicaçóes em tais situaçóes.

O segundo bloco desenvolve a comunicaça enquanto promotora do progresso. Para isso, parte do conceito da aldeia global do canadense Marshall Mcluhan ( p. 143 e s5. i, passando pelas perspectivas de Norbert Wiener ( $p$. 157 ) e Z. Brzezinski ( p. 154 ) para estabelecer a abertura do campo a telemática e todas as suas consequências. Voltando às suas raizes, Mattelart relembra os estudos do norte-americano Herbert Schiller e suas denuncias sobre a manipulação ideológica que o dominio das tecnologias de comunicaçắo provocavam em todo o mundo ( originando, inclusive, os estudos do próprio Mattelart ) até se chegar à discussajo, quase que infrutifera, nos dias de hoje. dos conceitos degladiados nos anos 70: o livie fluxo de informaçato, defendido pelos Estados Unidos e Inglaterra, sobretudo, e a nova ordem da informaçà, defendida pelos paises năo-alinhados, os do Terceiro Mundo e boa parte das naçốes ligadas à UNESCO que, tendo assumido tal posicionamento, acabou castigada com o corte de verbas internacionais, notadamente os subsidios dos próprios Estados Unidos ( ver em especial, p5, 167, 195 e 55,221 e s5. )

O bloco se encerra com a retomada do debate dos anos sessenta e as 
noçóes de subdesenvolvimento e desenvolvimento, para reexaminar o uso da teleducaçăo e, especialmente, da educaçăo rural, largamente aplicada em países como a India e mesmo na América Latina, a partir das experiências de Wilbur Schramm, assumidas pelos programas da Aliança para o Progresso dos tempos de John Kennedy (aliás, sempre me lembro de que uma cópia do filme Vidas Secas, de Nelson Pereira dos Santos, sobre o
romance de Graciliann Ramos, disponivel pelo Cube de romance de Graciliano Ramos, disponivel pelo Clube de Cinema de Porto Alegre, e reiteradas vezes exibida em sessóes privadas do cineclube ou em reuniobes estudantis, ainda na dếcada dos setenta, tinha na sua ponta um documentário sobre os "beneficios" da Aliança e seus projetos em nosso continente, do que herdariamos, depois de encerrado o programa, uma iniciativa dos militares de entáo, o Projeto Rondon, que interiorizava profissionais liberais e estudantes universitarios e de III grau, na tentativa de modernizar as populaçóes rurais de nosso interior: ironia suprema.... )

A última discussaio trazida por Mattelart neste bloco envolve o conceito neo-liberal do livre comércio, para concluir que se vive um "diálogo de surdos" e que apenas a superaça da fase que ele identifica como a da televisio da grande maioria / que / depende sempre das imagens dos outros' ( $p .217$ ), através da institucionalizaçấo das grandes redes de comunicaçầ, poderá vencer a continua dominaçà Para Mattelart, surpreendentemente, năo chega a ser preocupante o surgimento da "empresa rede', que ele abordará especialmente no décimo capitulo do livro, e que podemos aproximar, sem sombra de dúvida, de realidades como a da carla vez mais extensiva Internet. Para ele, aliás, é neste momento que se concretiza o conceito de espaço-mundo $e$, conseqüentemente, da comunicaçato-mundo, ultrapassando, inclusive, em sua ótica, as antigas divisôes entre Norte e Sul.

E admirável a maneira dinámica pela qual o autor consegue articular náo só os trếs blocos da obra quanto os conceitos abordados em cada um deles: Isso fica evidente, por exemplo, na conexăo dessa terceira parte com as demais, da mesma forma que sua estruturaçăo interna, exatamente porque, para atingir a questão da globalização, ele vai partir de seu ponto conceifualmente oposto, a Teora Critica que a Escola de Frankfurt desenvolveu, a partir da década dos vinte, na Alemanha e, posteriormente, nos anos 40-50
nos Estados Unidos.

Sob tal ótica, Matfelart evidencia que, embora disponivel pelo menos desde 1947, quando do desenvolvimento do conceito por Adorno e Horkheimer, a preocupaçào com a chamada indústria cultural só atingiu a Europa no final da década dos setenta, mais especificamente a França de 1978, quando seu governo deu-se conta do reflexo comercial e industrial que tais práticas possuíam. Assim, das perspectivas de Henri Lefebvre ( $p .228$ ) al Michel foucault, a França foi a primeira naçăo européia a estabelecer um projeto especifico para o desenvolvimento de sua própria indústria cultural, o 
que nấo implicou apenas em debates ridículos como aquele ainda relativamente presente sobre os estrangeirismos na comunicaçăo visual francesa dos out-doors, mas, especialmente, a formulaçáo de um planejamento de médio e longo curso de fomento a indústrias ligadas ao entretenimento, bem como às tecnologias de comunicaçâo, capazes de dar a França capacidade de competiçajo com as demais naçóes ditas industrializadas, notadamente os Estados Unidos e a Inglaterra. Só assim se explicam os progressos espaciais franceses e suas consequências, dentre as quais as explosôes atổmicas em Mururoa, que tanta polêmica internacional tềm provocado.

Aprofundando o conceito de descentralismo e indagando-se criticamente sobre o conceito da condiçăo de outro como um risco de nova res-centralizaçăo hegemonizante, Mattelart discute sobretudo a globalizaçio enquanto "modo de gestäo" ( p. 248-249), chamando a atençấo para as perspectivas do holismo ( p. 251 ) e as teorias da Terceira Onda de Alvin Toffler ( p. 255).

Nas conclusōes da obra, Mattelart realiza verdadeiro inventário do debate contemporầneo sobre a comunicaçāo, Destacando a ressignificaçằo do conceito da singularidade ( p. 264 ) e reconhecendo a permanência de espaços de interesses contraditórios ( p, 268), o sociólogo mostra que, de modo geral, ainda sajo escassas as reflexbes criticas mais profundas sobre o papel dos midia. Ao mesmo tempo, também náo se tem refletido conseqüentemente sobre o papel que o intelectual pode desenvolver na sociedade contemporânea ( $p$. 271 ), sobretudo na beligerância evidente que a liberdade e a democracia mantém. No horizonte do atual estágio, está a perspectiva do consumidor enquanto co-produtor da realidade ( $p .279)$, mas para isso devem-se repensar as teorias clássicas, desde a da manipulaçào ( teona do projétil ) até a do two step flow (duplo fluxo) da informaçáo. A leitura negociada ( p, 280-281). as redes de antidisciplina idealizadas por Michel de Certeau ( p. 285 ) - cuja obra, aliás, a mesma Editora Vozes acaba de colocar no mercado editorial brasileiro - e o encaminhamento de soluçóes para o problema polissémico que o conceito da comunicaçáo nos oferece ( $p .288$ ) sào alguns dos desafios que se apresentam. Para ele, só o esquecimento das tiçóes da História podem manter a oposiçăo entre o internacional e o nacional $(p .289)$, e neste sentido, o grande debate, no fundo, permanece: a Comunicaçào continua sendo um grande enigma ( p, 292).

O volume contém, alêm de um muito bem elaborado indice remissivo de nomes próprios e conceitos, o que facilita sua consulta futura, um excelente Apéndice com o desenvolvimento cronológico das conquistas tecnológicas direta e indiretamente ligadas aos processos de informaçầo e comunicaçấo, e isso desde a publicaçăo, em 10 de janeiro de 1788 , em Londres, do jornal The Times, com informaçoes procedentes de outras cidades ( com diferenças de menos de um mês entre o acontecimento e sua noticiabilidade) até o 
triste episódio da Guerra do Colfo e a retomada do pool jornalistico só quebrado graças às inéditas imagens transmitidas para todo o mundo pelas caimeras da CNT.

Em sintese, Comunicação-Mundo não é apenas uma revisằo critica da história da Comunicaçáo no planeta, quanto uma revisấo de perspectiva de sua abordagem do próprio autor. E se Armand Mattelart já era, em geral, brilhante nos ensaios precedentes, aqui ele se supera. Comunicasaáo-Mundo é um livro de revisâo, mas, por isso mesmo, e sobretudo, uma obra de prospectiva. Abre com qualificaçăo a coleção Horizontes da Globalizaçāo que a Vozes iniciou, reunindo trabalhos que tanto assumem a perspectiva da pós-modernização, como Mike Featherstone (Cultura global Nacionalismo, Globalizaçâo e Modernidade), quanto discutem esses mesmos conceitos, como Serge Latouche (A Ocidentalizaçáo do Mundo) ou Jean Chesneaux (Modernidade-Mundo), na dupla perspectiva de ensaistas europeus, notadamente franceses, e norte-americanos, permitindo o confronto das idélas e das perspectivas.

MATTELART, Armand - Comunicaşăo-Mundo História das Idéias e das Estratégias. Retrópolis; Vozes, 1994 - 320 páginas.

\author{
Antônio Hohlfeldt \\ Pholessar de Teoria da Comunicachio na FMMECOSPUCRS, \\ Doutorando em Literatura Brasileira pela PUCRS, \\ critico literário e autor de textos ficrionais para criaricas e jowens.
}

